\title{
A fundação da Licenciatura em Música da Universidade Federal de Campina Grande: apontamentos históricos
}

\author{
The foundation of the Federal University of Campina Grande's \\ Music Teacher Education Program: historical notes
}

João Valter Ferreira Filho iDa

\section{Resumo}

O presente trabalho lança mão de pesquisas bibliográficas, documentais e junto a fontes orais para apresentar os principais traços do longo processo histórico que culminou na fundação da Licenciatura em Música da Universidade Federal de Campina Grande, ocorrida no ano de 2009. Partindo de registros historiográficos e das memórias trazidas à tona por pessoas-fonte alcançadas no decorrer da pesquisa, o histórico elaborado em torno do processo de fundação do curso - que até a presente pesquisa consistia em uma expressiva lacuna nos registros de história e memória da educação musical campinense - permite, ainda, perceber a relevância da criação de um curso superior para a formação de professores no cenário local, ao passo que também revela as principais opções assumidas quando de sua instauração naquela universidade.

Palavras-chave: História da Educação Musical. Ensino Superior de Música. Licenciatura em Música. UFCG.

\section{Abstract}

This work uses bibliographic, documentary and oral research to present the main features of the long historical process that culminated in the foundation of the Federal University of Campina Grande's Music Teacher Education Program, occurred in 2009. Starting from historiographic sources and memories brought by people reached in the course of the research, the history elaborated around the process of founding the course - which until the present research consisted of an expressive gap in the history and memory records of the musical education of Campina Grande - it also allows us to perceive the relevance of creating a higher education course for the training of teachers in the local scenario, while it also reveals the main options assumed when it was established at that university.

Keywords: History of Music Education. Music Teacher Education Program. Degree of Music. UFCG.

a Doutor em Música (UFPB). Professor da Universidade Federal de Campina Grande. 
Resumen

El presente trabajo hace uso de la investigación bibliográfica, documental y oral para presentar los principales rasgos del largo proceso histórico que culminó con la fundación de la Licenciatura en Música en la Universidad Federal de Campina Grande, que se llevó a cabo en 2009. A partir de registros historiográficos y memorias presentadas por personas de su origen, alcanzadas en el transcurso de la investigación, la historia elaborada en torno al proceso de fundación del curso - que hasta la presente investigación consistía en un vacío expresivo en los registros de la historia y la memoria de la educación musical de Campina Grande - también nos permite percibir la relevancia de crear un curso de educación superior para la formación de docentes en el escenario local, al tiempo que revela las principales opciones assumidas cuando se estableció en esa universidad.

Palabras clave: Historia de la Educación Musical. Educación Musical Superior. Graduación en Música. UFCG.

\section{Introdução}

A Universidade Federal de Campina Grande - UFCG - tem sua origem em 1952, ano da fundação da Escola Politécnica da Paraíba, instituição de nível superior que ofertava, inicialmente, somente o curso de Engenharia Civil. Ao longo da década de 1960, sobretudo a partir da gestão do professor Lynaldo Cavalcante, a instituição passou a se estruturar e alcançar grande importância no contexto das pesquisas de inovação tecnológica no país, consolidando-se por meio da implementação dos cursos de Engenharia Mecânica e dos mestrados em Engenharia Elétrica e Engenharia de Sistemas. Em 1968, a Politécnica ganhou destaque nacional ao instalar em seu laboratório o primeiro computador do Nordeste, um IBM 1130 do tipo mainframe (MOTA, 2017). Em 1973, juntamente com a Faculdade de Ciências Econômicas de Campina Grande, foi incorporada à Universidade Federal da Paraíba, passando a configurar o Campus II desta IES. Posteriormente, após 29 anos de funcionamento vinculados à UFPB, no ano de 2002 o campus de Campina Grande foi desmembrado da sede e, em conjunto com os campi situados nos municípios de Patos, Cajazeiras e Souza, passou a constituir a Universidade Federal de Campina Grande - UFCG.

A UFCG conta atualmente com sete campi, englobando as microrregiões do Agreste, Brejo e Sertão paraibanos, situados nas cidades de Patos, Souza, Cajazeiras, Rev. Caminhos da Educação: diálogos, culturas e diversidades, Teresina, v. 3, n. 1, p. 35-52, jan./abr. 2021 
Sumé, Pombal, Cuité e Campina Grande, sendo esse último o Campus Central. A IES oferta 77 cursos de graduação, 12 doutorados e 27 mestrados, atendendo a uma quantidade total de aproximadamente 19.000 alunos e contando com o trabalho de aproximadamente 1.800 professores e 2.100 servidores técnico-administrativos (UFCG, 2020).

A Licenciatura em Música da UFCG - LicMus/UFCG - é um curso ofertado apenas no Campus Central da universidade, situado no bairro de Bodocongó, município de Campina Grande. As aulas são alocadas em salas distribuídas em quatro blocos do campus, sendo quinze delas localizadas no Bloco BW - onde também se encontram o auditório, o laboratório de áudio, as salas dos professores e as secretarias administrativas dos cursos de bacharelado e licenciatura -, duas salas no Bloco BZ, um laboratório para a construção de instrumentos musicais alternativos situado no Bloco BH e um laboratório de informática situado no Bloco BA. Dentre as salas de aula situadas no Bloco BW, seis são destinadas a aulas coletivas, sendo compartilhadas com os outros cursos que compõem a Unidade Acadêmica de Arte - o Bacharelado em Arte e Mídia e o Bacharelado em Educomunicação. Três delas estão equipadas com TV, duas com equipamentos de projeção de imagem, três com pianos e cinco com quadros pautados. No mesmo prédio, nove outras salas são destinadas a aulas individuais de instrumento ou orientações de pesquisa, ficando cada uma dessas salas sob a responsabilidade de um ou dois professores específicos.

O ingresso na LicMus/UFCG se dá no segundo período de cada ano, em razão da operacionalização do THE - Teste de Habilidades Específicas, geralmente realizado no mês de junho. Para cursar a licenciatura, o aluno deve escolher um instrumento musical como habilitação, opção que deve ser manifestada ainda quando de sua inscrição no THE, já que haverá provas específicas a fazer a esse respeito. As habilitações ofertadas pela LicMus/UFCG são: canto, piano, violão, flauta doce, violino, viola, violoncelo, contrabaixo acústico, saxofone, clarinete, bombardino, trombone e tuba ${ }^{1}$.

O quadro docente do Curso conta atualmente com 14 professores efetivos, sendo oito doutores, cinco mestres e um especialista, que também atuam

\footnotetext{
${ }^{1}$ Além dessas 13 habilitações, o Bacharelado oferece também Regência, Produção Musical e Composição.

Rev. Caminhos da Educação: diálogos, culturas e diversidades, Teresina, v. 3, n. 1, p. 35-52, jan./abr. 2021
} 
concomitantemente no Bacharelado em Música da Instituição. Nesse quadro, oito docentes se dedicam prioritariamente - mas não exclusivamente - às disciplinas referentes a seus instrumentos de domínio, ao passo que quatro costumam se alternar nos componentes classificados pelo PPC como "matérias teóricas".

A LicMus/UFCG conta atualmente com 82 alunos regularmente matriculados, sendo 60 do sexo masculino e 22 do sexo feminino, o que confirma a tendência verificada pelos estudos de Soares, Schambeck e Figueiredo (2014) e Mateiro (2007), que sinalizam a predominância de licenciandos do sexo masculino na formação docente da área no contexto brasileiro. A faixa etária média dos alunos ativos é de 24 anos de idade, situada entre os extremos de 19 e 56 anos. A maior parte dos licenciandos $(50$ indivíduos $=60,9 \%$ ) reside em Campina Grande, ao passo que 36,5\% (30 indivíduos) possuem endereço fixo distribuídos por sete cidades do interior da Paraíba e 2,4\% (dois indivíduos) em duas cidades do estado de Pernambuco.

\section{Antecedentes históricos da fundação do Curso: o Núcleo de Extensão Cultural do Campus II da UFPB}

De acordo com Jordão (2012, p. 48), a partir de meados da década de 1970 verifica-se uma notável expansão das atividades culturais no âmbito da Universidade Federal da Paraíba. Esse incentivo a atividades culturais diversas deve ser entendido como parte de um complexo cenário sociopolítico no qual o governo militar buscava, de certa forma, estabelecer meios de apaziguamento dos ânimos sociais por meio da oferta de benefícios diversos, especialmente direcionados à classe média. Naquele contexto, o Ministério da Cultura (MINC) lançou, em 1975, a Política Nacional de Cultura (PNC), um ambicioso plano de desenvolvimento que tinha por objetivo promover a institucionalização e reorganização de diversos setores da área cultural do país.

Com algumas relevantes exceções - notadamente aquelas que se mostravam especialmente resistentes ao acordo com a ideologia do regime - de modo geral as universidades passaram a ser vistas como parceiras em potencial para a 
implementação daquela Política Nacional de Cultura. Professores outrora demitidos por divergências políticas foram recontratados, grandes quantidades de bolsas de estudo foram autorizadas, inclusive para cursos no exterior, a pesquisa na área da cultura passou a ter financiamento, houve o incentivo a publicações, exposições e festivais universitários, cursos de profissionalização para produtores culturais e equipes técnicas, etc. (JORDÃO, 2012, p. 53).

Foi naquele contexto sociopolítico de incentivo à expansão das atividades relacionadas à arte e à cultura que foram criados os dois primeiros cursos de graduação da área de Arte na Universidade Federal da Paraíba (UFPB): os cursos de Licenciatura Plena em Educação Artística (com habilitações em Música, Artes Plásticas e Teatro) e o Bacharelado em Música. Tal iniciativa, encabeçada diretamente pelo então reitor da instituição, professor Lynaldo Cavalcante, veio a ser incrementada, ainda, por meio da criação de quatro instâncias diretamente vinculadas à pesquisa e extensão na dimensão da arte e da cultura: o Núcleo de Arte Contemporânea - NAC, o Núcleo de Teatro Universitário - NTU, o Núcleo de Produção e Pesquisa da Cultura Popular - NUPPO e o Núcleo de Documentação Cinematográfica - NUDOC (JORDÃO, 2012, p. 55). Tanto os cursos de graduação quanto os núcleos de pesquisa e extensão foram implementados no Campus Central da Universidade, situado em João Pessoa, com o apoio técnico de profissionais da Fundação Nacional das Artes (FUNARTE) e o assessoramento de diversos profissionais convidados, muitos dos quais acabaram permanecendo como parte do quadro docente dos cursos recém-criados. ${ }^{2}$.

Três anos depois, como iniciativa de incentivo à interiorização dessa política de ampliação do apoio à produção cultural do estado, foi criado também o NEC Núcleo de Extensão Cultural da UFPB - a ser implementado no Campus II da Universidade, situado no município de Campina Grande. Para sua implementação, a Pró-Reitoria para Assuntos do Interior da UFPB, convidou José Cláudio Baptista, então professor da Fundação Universidade Regional do Nordeste - FURNE

\footnotetext{
${ }^{2}$ Nascimento (2014) assinala que o documento localizado por suas pesquisas a respeito da criação do NEC teria sido a Resolução CONSEPE/UFPB n.35 $\square$ 1991. Entretanto, como o núcleo sabidamente se encontrava em atividade desde o ano de 1978, é de se supor que essa resolução mencionada não seja a original da época de sua fundação. De todo modo, fato é que a presente pesquisa não localizou em arquivo algum nem a resolução mencionada por Oliveira nem qualquer outra relacionada à implementação do NEC. Uma solicitação formal para a 0 recebimento de informações a esse respeito foi encaminhada ao SODS/UFPB, departamento responsável pelo arquivo de documentação daquela IES. Sem sucesso.

Rev. Caminhos da Educação: diálogos, culturas e diversidades, Teresina, v. 3, n. 1, p. 35-52, jan./abr. 2021
} 
(NASCIMENTO, 2014, p. 11). O NEC, então, foi instalado provisoriamente em um edifício cedido pelo governo do estado, local onde atualmente está localizado o Museu Histórico. Alguns anos depois, no início da década de 1980, as atividades do núcleo foram transferidas para o Teatro Municipal Severino Cabral, em função de um convênio celebrado com a Prefeitura Municipal.

Os trabalhos foram operacionalizados por meio de cursos de teatro, música e artes visuais, ministrados tanto por professores convocados a partir da cena artística local, como também por educadores vindos de várias outras partes do país, e ofertados gratuitamente à comunidade local. De acordo com Nascimento (2014, p. 12), os primeiros cursos a serem ministrados regularmente pela instituição foram: (1) Fotografia, sob a responsabilidade de Roberto Coura; (2) Artes Plásticas, ministrado por Antônio Barbosa Guimarães; e (3) Teatro, cuja condução era compartilhada por dois importantes nomes da dramaturgia local: Hermano José e Eneida Agra Maracajá. Logo seriam implementados também os cursos de Teoria e Percepção Musical, História da Música, Música e Criatividade e aulas de práticas instrumentais diversas, além da criação de duos, trios, grupos de câmara variados e um grande agrupamento misto, do qual haveriam de participar todos os alunos do Núcleo, sob a regência de Fernando Rangel. A direção geral do NEC ficou primeiramente a cargo do próprio professor José Cláudio Baptista, sendo posteriormente assumida por outros educadores já envolvidos no projeto, em sucessivas gestões de curta duração. Dentre os diretores daqueles primeiros anos de existência do NEC registram-se Antônio José Madureira, Hermano José, Carlos Allan Peres da Silva, Elisabeth Marinheiro, Fernando José Torres Barbosa, Eneida Agra Maracajá, dentre outros.

Dois grupos de reconhecida atuação no cenário artístico regional foram convidados a assumir o planejamento e implementação dos cursos da área de música: o Quarteto Telemann e Quinteto Armorial, ambos com origem em Recife/PE. Para tanto, todos os seus componentes foram contratados como professores efetivos do NEC/UFPB. O Quarteto Telemann, que já vinha desenvolvendo um trabalho anterior nos cursos da FURNE, dedicava-se, inicialmente, ao ensino e à performance da flauta doce, trabalhando prioritariamente com interpretação de música antiga. Pouco tempo depois, a partir da incorporação do violonista Edvaldo Eulálio Cabral Rev. Caminhos da Educação: diálogos, culturas e diversidades, Teresina, v. 3, n. 1, p. 35-52, jan./abr. 2021 
em seu quadro e a posterior inclusão de um violoncelo, o grupo passou a designar-se Cordas e Sopros, expandindo seu âmbito de atuação também para cursos e performance de instrumentos de cordas e iniciando um relevante trabalho em torno do estudo, ensaio e apresentação de repertório de música brasileira. Quanto ao papel do Quarteto Telemann naqueles primeiros tempos do NEC, Romero Ricardo Damião de Araújo, um de seus fundadores, assinala que:

Chegamos todos juntos, praticamente. Iniciamos nossos trabalhos no Instituto Histórico, um edifício belíssimo, em frente à Catedral de Campina Grande. A universidade forneceu a estrutura básica necessária, dentro do que era possível naquele momento: havia um diretor, um secretário, funcionários e nós, professores. Começamos, então, de uma maneira particular, por assim dizer. Cada professor ficou responsável por montar seu próprio curso, cada um fazendo seu próprio programa e já testando na prática com a comunidade, mostrando à comunidade que os artistas ali tinham um projeto, digamos assim, para esse novo horizonte de artes na cidade (ARAÚJO, 2020. Informação verbal).

Os outros professores responsáveis pelos cursos de música do NEC eram membros do Quinteto Armorial, um grupo fundado pelo escritor e dramaturgo Ariano Suassuna, que atuava como ramo musical do Movimento Armorial, projeto que deu grande destaque à cultura nordestina no cenário artístico brasileiro em meados dos anos setenta. De acordo com Carneiro (2017):

O ponto de partida desses trabalhos tinha como premissa a criação de uma "música erudita brasileira baseada nas raízes populares". [...] A orientação musical de Ariano Suassuna compreendia uma ideia filosófica e uma concepção de cultura brasileira que privilegiava a sonoridade e os timbres da musicalidade do "povo" enquanto proposta e diretriz para a criação de uma música de concerto, que pudesse trazer alguma marca especificamente brasileira (CARNEIRO, 2017, p. 19).

À época do convite para a atuação no NEC em Campina Grande, o grupo era composto pelos músicos Fernando José Torres Barbosa (flauta transversal e marimbau), Fernando Farias (flauta transversal), Antônio Carlos Nóbrega de Almeida (violino), Antônio José Madureira (violão) e Edilson Eulálio Cabral (violão). A respeito do convite e da instalação das atividades do Quinteto no interior da Paraíba, Fernando Barbosa assinala que:

A gente possuía um trabalho consolidado e muito intenso em Pernambuco, com Ariano e também com outros artistas de lá, claro. Mas quando Lynaldo Cavalcanti nos convidou para vir para Campina, percebemos ali a oportunidade de divulgar ainda mais aquela música da gente. E como ia ser numa universidade, uma coisa estruturada e tal. Então decidimos vir. Alguns ficariam permanentemente em trânsito Recife-Campina, outros Rev. Caminhos da Educação: diálogos, culturas e diversidades, Teresina, v. 3, n. 1, p. 35-52, jan./abr. 2021 
optaram por residir em João Pessoa. Eu vim logo pra cá de vez (BARBOSA, 2020. Informação verbal).

Durante aproximadamente dois anos, os membros do Quinteto Armorial trabalharam intensamente no NEC, ministrando aulas, desenvolvendo pesquisas de repertório e realizando gravações diversas. No ano de 1980, com o encerramento de suas atividades, alguns de seus componentes optaram por não permanecer mais vinculados ao núcleo, ao passo que outros, tais como o professor Fernando Barbosa e o violonista Edilson Eulálio, continuaram ministrando cursos regularmente.

Ao passo que os professores do Quarteto Telemann e do Quinteto Armorial direcionavam sua atuação no NEC à música instrumental, a diretoria do núcleo convidou os professores Nelson Mathias e Célia Bretanha, que à época eram vinculados ao Coral do SESI de Brasília, para se instalarem em Campina Grande, a fim de ministrar cursos na área de técnica vocal e promover o crescimento da música coral na cidade. Assim como os demais músicos convidados para o projeto, Nelson Mathias e Célia Bretanha já possuíam sólidas carreiras artísticas. Nelson à época já era reconhecido no universo coral como compositor e regente premiado nacional e internacionalmente, enquanto Célia, sua esposa, já havia sido professora em diversas universidades do país e participado de especiais musicais em redes de TV de alcance nacional.

Ao longo de quatro anos - entre 1978 e 1982 - a atuação desses dois educadores à frente do Coral da Universidade Federal da Paraíba - Campus II deu início a um forte movimento coral na cidade de Campina Grande, ocasionando a fundação de numerosos outros grupos de canto coletivo em igrejas, escolas e centros comunitários, muitos dos quais continuaram cultivando e divulgando o canto coral em Campina Grande após sua partida, tais como o FACMADRIGAL, ligado à Fundação Artístico-Cultural Manuel Bandeira e dirigido por Sérgio Telles, o Coral De Repente Canto, regido por Fernando Rangel, o Coral Viva Voz, vinculado ao Centro Cultural de Campina Grande, que foi coordenado e regido por Vladimir Silva na década de 1990, assim como o Grupo Vocal Nós em Voz, o Coral do Carmo e Coral Canto da Gente (FURNE), coordenados por José Claudio Baptista (NASCIMENTO, 2014). No âmbito da universidade, esse trabalho encontrou continuidade por meio Rev. Caminhos da Educação: diálogos, culturas e diversidades, Teresina, v. 3, n. 1, p. 35-52, jan./abr. 2021 
do Coro EnCanto, atualmente regido pelo professor Lemuel Guerra. Após a criação dos cursos de Graduação em Música da UFCG (Licenciatura e Bacharelado), o professor Vladimir Silva vem se dedicando ao desenvolvimento do canto coral na instituição, com destaque para os trabalhos do Coro de Câmara da UFCG e do LabMus, iniciativa que integra a atuação de diversos coros regidos por alunos do bacharelado e da licenciatura em música com a participação da comunidade campinense em faixas etárias diversas.

Como é possível perceber, a atuação do NEC em Campina Grande representou para a comunidade local um importante meio de aperfeiçoamento e diversificação das práticas musicais, dando oportunidade de acesso a experiências individuais e coletivas que marcariam profundamente o perfil cultural da cidade. Posteriormente designado como DART - Departamento de Arte - aquele núcleo permaneceu com suas atividades em pleno funcionamento ao longo dos anos posteriores, alcançando maior estruturação, inclusive com relação às suas instalações físicas, após o ano de 1998, quando foi criado o Bacharelado em Arte e Mídia, que absorveu todos os professores de música do NEC e incorporou em seu currículo cursos relacionados à tecnologia musical, tais como Protocolo MIDI e editoração musical (SILVA, 2020).

No ano de 2002, o Campus II se emancipou da UFPB, passando a constituir o Campus Central da recém-criada Universidade Federal de Campina Grande. Esse viria a ser o passo inicial para a criação dos cursos de graduação em música desta universidade, conforme será exposto no tópico a seguir.

\section{A fundação da Licenciatura em Música da UFCG}

De acordo com o depoimento de Silva (2020), as primeiras articulações em prol da criação de um curso superior de música na UFCG surgem a partir do ano de 2007, dentro do contexto de expectativa pela expansão dos cursos das universidades federais, fato que viria a se concretizar por meio do programa REUNI.

Muito embora eu estivesse morando em Teresina, onde já trabalhava há mais de 15 anos como professor da Universidade Federal do Piauí, eu sempre continuei ligado por relações de amizade aos professores que atuavam no DART da UFCG. Então, por volta 
de 2007, em conversa com os professores Carlos Allan e Fernando Barbosa, eu soube que eles estavam planejando a criação de um curso de Tecnólogo em Música. Ali eu já argumentei com eles que seria muito melhor pensar num curso de graduação licenciatura/bacharelado, e que nós deveríamos focar nisso ao invés de nos direcionarmos a um curso de bacharelado, que é mais curto, mas, como você sabe, não tem o mesmo perfil (SILVA, 2020. Informação verbal).

Movidos pela perspectiva de transformar os cursos livres do DART em um curso de graduação, alguns professores passaram, então, a procurar meios de articular a fundação de um curso superior para a área de música na UFCG. A primeira reunião em torno dessa decisão contou com a participação dos professores Fernando Barbosa, Carlos Allan Peres, Marisa Nóbrega, Luciênio Teixeira, Maurílio Rafael e Vladimir Silva, que, sendo à época professor da Licenciatura em Música da Universidade Federal do Piauí, havia sido convidado para expor as possibilidades de implementação de uma graduação em música com perfil de bacharelado e/ou licenciatura em Campina Grande, sua terra natal. Foi, então, constituída uma comissão para a elaboração de uma nova proposta curricular, sob a coordenação do professor Maurílio Rafael, tendo como demais membros os professores Fernando Barbosa e Carlos Allan Peres. De acordo com Carlos Allan Peres:

Naquele primeiro momento nós pensamos em criar um curso guarda-chuva, que abrangesse tanto 0 aspecto da performance quanto os estudos voltados para a tecnologia musical de ponta e também a possibilidade de os egressos estarem preparados para dar aulas de música em qualquer lugar. A ideia era, então, um curso bastante amplo, que nós denominamos mesmo de Curso Superior de Música. Só isso (PERES, 2020. Informação verbal).

A proposta consistia em um curso com duração mínima de oito períodos, sendo que nos quatro primeiros os alunos deveriam cumprir um tronco comum direcionado aos estudos teóricos e prática instrumental. $\mathrm{Na}$ segunda metade do currículo os percursos seriam direcionados ou ao aprofundamento da performance ou a estudos mais relacionados ao ensino. Com o apoio do então Pró-Reitor de Ensino, professor Vicemário Simões, as propostas da comissão foram encaminhadas ao MEC e aprovadas como parte do REUNI para a UFCG. O curso foi oficialmente criado por meio da Resolução CSE n. 03, de 16 de agosto de 2008. Como é possível verificar no documento, seguindo as proposições originais de sua comissão de criação, 
naquele primeiro momento a graduação em música da UFCG consistia em apenas um único curso, sem definição específica quanto à sua modalidade, ou seja, se seria bacharelado ou licenciatura:

Art. $2^{\circ}$. O Curso de Música tem, como finalidade, conferir o grau de Licenciado ou de Bacharel em Música aos alunos que cumprirem as determinações constantes no Projeto Pedagógico do Curso e demais normas da Instituição (UFCG, 2008, grifo meu).

A mesma Resolução estabelecia o início das atividades do curso para o segundo semestre letivo do ano de 2009. Sendo assim, os meses de agosto a dezembro de 2008 foram dedicados à realização dos concursos para a composição do quadro docente e demais planejamentos referentes ao funcionamento geral do curso. Professores que já trabalhavam com disciplinas relacionadas a práticas musicais no Bacharelado em Arte e Mídia - único curso de graduação na área de Arte existente na instituição até aquele momento - foram designados para o Curso de Música e foram abertas cinco novas vagas para concurso, oriundas do REUNI. Posteriormente obteve-se também mais duas vagas de redistribuição.

O quadro abaixo apresenta a relação dos professores fundadores do Curso de Música da UFCG, bem como sua área de atuação:

Quadro 1 - Professores-fundadores da LicMus/UFCG

\begin{tabular}{|c|c|c|}
\hline PROFESSOR & ORIGEM DA VAGA & ÁREA DE ATUAÇÃO \\
\hline Carlos Allan Peres & Bacharelado em Arte e Mídia & Tecnologia Musical \\
\hline Francisco Cunha Metri & Bacharelado em Arte e Mídia & Flauta doce \\
\hline Romero Damião & Bacharelado em Arte e Mídia & Flauta doce \\
\hline Fernando Barbosa & Bacharelado em Arte e Mídia & História da Música \\
\hline Marisa Nóbrega & Bacharelado em Arte e Mídia & Educação Musical \\
\hline Joelson Miguel & Bacharelado em Arte e Mídia & Contrabaixo \\
\hline Alba Valéria & Bacharelado em Arte e Mídia & Clarinete/Saxofone \\
\hline Francieudo Torres & Concurso/REUNI & Violoncelo \\
\hline Angela Perazzo & Concurso/REUNI & Violino/viola \\
\hline Jorge Ribbas & Concurso/REUNI & Violão \\
\hline Jean Márcio Souza & Concurso/REUNI & Trombone/tuba/bombardino \\
\hline Maria Di Cavalvanti & Concurso/REUNI & Piano \\
\hline
\end{tabular}

Rev. Caminhos da Educação: diálogos, culturas e diversidades, Teresina, v. 3, n. 1, p. 35-52, jan./abr. 2021 


\begin{tabular}{|c|c|c|}
\hline Vladimir Silva & Redistribuição/UFPI & Regência/canto \\
\hline Liduíno Pitombeira & Redistribuição/UFPB & $\begin{array}{c}\text { Composição/matérias } \\
\text { teóricas }\end{array}$ \\
\hline
\end{tabular}

Fonte: Elaborado pelo autor.

Durante todo o primeiro semestre de 2009, os membros do recém-formado corpo docente se dedicaram integralmente ao planejamento e elaboração do que viria a ser o Projeto Pedagógico do Curso de Música. Concomitantemente, os cursos de extensão na área de música, que continuavam sendo ofertados regularmente pelo DART desde a criação do NEC, passaram a contar com o trabalho dos professores recém-concursados. Contavam-se então aproximadamente 400 alunos de extensão em música no Departamento (ARAÚJO, 2020).

Conforme previsto em sua Resolução de criação, a primeira turma do Curso de Música da UFCG iniciou suas atividades no período letivo 2009.2, com alunos selecionados unicamente a partir da nota do ENEM. Entretanto, de acordo com o professor Vladimir Silva, os professores logo perceberam que grande parte dos candidatos que haviam sido aprovados para ingressar no curso não tinham realmente noção da verdadeira natureza do Curso:

\begin{abstract}
A Universidade estabeleceu 40 vagas para o curso. [...] Completou-se essas vagas muito rapidamente, pois não houve teste de seleção. Mas aí a gente vai observar que dentre aqueles alunos da primeira turma que entrou, pouquíssimos, de fato, entenderam que se tratava de um curso superior. O que nós tínhamos ali eram pessoas que achavam que estavam entrando em cursos de extensão ou que a filosofia seria aquela filosofia mais "light" [...]. Não havia ainda aquela concepção de que um curso superior na área de música havia sido iniciado na UFCG. [...] Então, como esses alunos não tinham a qualificação mínima que nós queríamos, não havia um "padrão zero" a partir do qual a gente fosse construir um currículo com eles. Aí a gente ofertou um curso de nivelamento (SILVA, 2020. Informação verbal).
\end{abstract}

Naquele primeiro semestre, portanto, todos os alunos que haviam ingressado no Curso de Música da UFCG passaram a cursar um programa de nivelamento, ministrado pelo professor Vladimir Silva em três encontros semanais com duração de aproximadamente duas horas. O objetivo daquela iniciativa era o ensino dos conteúdos considerados fundamentais para que se pudesse posteriormente seguir no 
currículo superior propriamente dito. O depoimento do professor Fernando Barbosa ilustra o impacto causado por aquela situação junto ao corpo docente da época.

Eu me lembro que fiquei muito espantado, atônito mesmo. Mas não era assim, achando que o pessoal era ruim, ou não servia. Eu só achava que talvez a gente iria receber no curso superior alguns daqueles alunos que já vinham se destacando nos nossos cursos de extensão, que faziam muito sucesso há muito tempo. Só que não foi isso o que aconteceu exatamente. Acho que muita gente que tocava bem não tinha interesse em ter um curso superior. E o pior: o contrário também era verdade! (BARBOSA, 2020. Informação verbal).

O professor Vladimir Silva, responsável pela condução das aulas de nivelamento, salienta que aquele primeiro período foi permeado de tensões e indefinições:

Na verdade, foi um semestre bastante difícil, com muitos conflitos, porque a gente tinha que definir as áreas que esses alunos iriam atuar. Tinha aluno que não sabia tocar absolutamente nada. Queria começar do zero na área do canto, na área da flauta doce, na área do violão [...]. Foi um caos aquilo ali [...]. Veja que foram problemas de abrir um curso sem de fato ter um perfil, um projeto pedagógico totalmente definido e amarrado. (SILVA, 2020. Informação verbal).

Paralelamente àqueles desafios de dimensão pedagógica, um outro problema surgia no âmbito institucional. Uma análise técnica por parte da Pró-Reitoria de Ensino da Universidade apontou uma questão crítica no Programa Pedagógico do Curso: a inviabilidade da implementação de um curso superior que não se enquadrasse ou na categoria de bacharelado ou na categoria de licenciatura. Após reuniões de intenso debate, nos quais o Pró-Reitor defendia a criação apenas da licenciatura e o corpo docente insistia na criação também de um bacharelado, foi designada uma nova comissão de professores com o objetivo de desmembrar a proposta inicial. Foram elaborados, então, dois novos Projetos Pedagógicos distintos: a Licenciatura em Música, cujo funcionamento veio a ser oficializado e regulamentado por meio da Resolução CSE n. 08, de 27 de junho de 2012, e o Bacharelado em Música, regulamentado através da Resolução CSE n. 03, de 26 de abril de 2013.

A consequência prática daquela primeira entrada, conduzida de forma ainda assistemática, foi que uma quantidade expressiva de alunos acabou desistindo do curso, fosse em razão de dificuldades para o acompanhamento das disciplinas, fosse por alguma falta de identificação com a proposta do curso ou outras contingências de 
ordem pessoal. Os registros do Controle Acadêmico da UFCG revelam que, dentre os 40 alunos regularmente matriculados na turma 01 do Curso, do período letivo 2009.2, apenas 13 chegaram a concluir sua graduação, sendo 06 no Bacharelado e 07 na Licenciatura ${ }^{3}$.

A partir da entrada da segunda turma, que ocorreu no período letivo 2010.2, o curso passou a aplicar o THE - Teste de Habilidades Específicas - instrumento de seleção que, a partir de então, tem servido como requisito, juntamente com a nota do ENEM, para o ingresso na graduação.

Quanto à estrutura curricular dos dois cursos, foi preservada a essência do projeto original: a licenciatura e o bacharelado compartilham um tronco comum de disciplinas, separando-se paulatinamente no decorrer do itinerário formativo, sobretudo a partir do quinto período. Uma definição importante com relação ao perfil formativo assumido para a licenciatura em música foi a decisão de manter o curso vinculado à performance em uma ampla gama de possibilidades de instrumentos, de acordo com a área na qual o licenciando já exerce alguma atividade antes mesmo de ingressar na graduação.

\section{Considerações finais}

A LicMus/UFCG é um curso de grande importância no contexto cultural de Campina Grande e de todo o interior paraibano. É um curso jovem - com pouco mais de 11 anos de existência - mas que já apresenta resultados muito sólidos, tanto no que diz respeito à formação acadêmica quanto no que se refere ao cenário artístico. Nesse quadro, dados que temos levantado e que se encontram expostos em outros trabalhos de pesquisa mostram que o Curso tende a consolidar cada vez mais seu importante papel social dentro do contexto cultural de Campina Grande estendendo-se, ainda, para muito além dessas fronteiras ${ }^{4}$.

\footnotetext{
${ }^{3}$ Dados obtidos por meio de acesso ao Controle Acadêmico Online do Curso. Acesso em 25 jun. 2020.

${ }^{4}$ Refiro-me aqui a uma quantidade expressiva de TCC's que tenho orientado nos últimos anos, além de Comunicações Orais apresentadas em Congressos da ABEM e da ANPPOM, além de minha própria Tese de Doutorado, intitulada "Perspectivas para uma formação culturalmente contextualizada de professores de música: problematizações, reflexões e propostas a partir da Licenciatura em Música da UFCG" (FERREIRA FILHO, 2021).

Rev. Caminhos da Educação: diálogos, culturas e diversidades, Teresina, v. 3, n. 1, p. 35-52, jan./abr. 2021
} 
Sendo assim, pesquisas históricas que se debrucem sobre a trajetória e os processos de constituição identitária do Curso, evidenciando as iniciativas e os fazeres educativo-musicais de seus protagonistas, se caracterizam como contribuições essenciais a fim de que essa expansão institucional que vem sendo verificada ao longo dos anos possa ser acompanhada - e, quiçá, suportada e mesmo orientada - por uma robusta reflexão sociocultural.

Nesse panorama, espero que o presente trabalho possa vir a ser um contributo relevante para futuras pesquisas, abrindo espaço para novas interrogações, novas problematizações e, consequentemente, novas investigações em torno dessa importante instituição de formação pedagógico-musical do Nordeste brasileiro.

\section{Referências}

ARAÚJO, Romero Ricardo Damião. Depoimento oral concedido ao pesquisador João Valter Ferreira Filho. Campina Grande, junho de 2020.

BARBOSA, Fernando José Torres. Depoimento oral concedido ao pesquisador João Valter Ferreira Filho. Campina Grande, junho de 2020.

CARNEIRO, Francisco Luiz Jeaninne Andrade. Quinteto Armorial: timbre, heráldica e música. 2017. 225 f. Dissertação (Mestrado em Filosofia) - Universidade de São Paulo, São Paulo, 2017.

FERREIRA FILHO, João Valter. Perspectivas para uma formação culturalmente contextualizada de professores de música: problematizações, reflexões e propostas a partir da Licenciatura em Música da UFCG. 429 f. Tese (Doutorado em Música) Universidade Federal da Paraíba. João Pessoa, 2021.

JORDÃO, Fabrícia Cabral de Lira. O Núcleo de Arte Contemporânea da Universidade Federal da Paraíba 1978/1985. Dissertação (Mestrado em Artes Visuais) - Universidade de São Paulo, São Paulo, 2012.

MOTA, Wellington Santos. Caminhos para inovação: o caso UFCG, 2017. 29 slides. Disponível em: < https://silo.tips/download/caminhos-para-a-inovaao-o-casoufcg-wellington-santos-mota>. Acesso em 21 jul. 2020.

NASCIMENTO, Jeter Maurício da Silva. A Música no contexto universitário: um estudo da prática coral na UFPB, Campus II, entre 1978 e 1982. 48 p. 2014. Monografia de Conclusão de Curso (Bacharelado em Música) - Universidade Federal de Campina Grande, Campina Grande, 2014. 
PERES, Carlos Allan. Depoimento oral concedido ao pesquisador João Valter Ferreira Filho. Campina Grande, junho de 2020.

SILVA, Vladimir Alexandro Pereira da. Depoimento oral concedido ao pesquisador João Valter Ferreira Filho. Campina Grande, junho de 2020.

UNIVERSIDADE FEDERAL DE CAMPINA GRANDE. Câmara Superior de Ensino. Resolução n. 08/2008. Aprova a criação do Curso de Música, na Unidade Acadêmica de Artes do Centro de Humanidades do Campus de Campina Grande desta Universidade, e dá outras providências. Campina Grande, 2008. 